\title{
Dissolution Stability Study of Cefadroxil Extemporaneous Suspensions
}

\author{
Noelia L. Gonzalez Vidal',2,3, Patricia D. Zubata', Laura D. Simionato', \\ and Maria T. Pizzorno ${ }^{1,2}$ \\ 'Cátedra Control de Calidad de Medicamentos, Facultad de Farmacia y Bioquímica, Universidad \\ de Buenos Aires, Junín 956, 1113 Buenos Aires, Argentina. \\ ${ }^{2}$ Cátedra Control de Calidad de Medicamentos, Departamento de Biología, Bioquímica y \\ Farmacia, Universidad Nacional del Sur, San Juan 670, 8000 Bahía Blanca, Argentina.
}

e-mail:nlgvidal@uns.edu.ar

\begin{abstract}
Dissolution studies have become matter of great significance because, in most cases, drug dissolution is the rate-limiting step in the absorption process. As occurs with solid oral dosage forms, heterogeneous disperse systems (suspensions) could also have some problems with their in vitro dissolution.

The dissolution behavior of four different brands of cefadroxil extemporaneous suspensions available in the Argentinian market was evaluated. The deliverable volume, $\mathrm{pH}$, visual appearance, uniformity of dosage units, and assay were also studied.

Powders for oral suspension were stored under different aging conditions. Samples at room temperature and refrigerated conditions were taken at several time points to carry out the dissolution stability study during the expiration period of the reconstituted form. Marked differences were recorded with respect to in vitro dissolution behavior between the different products under evaluation.
\end{abstract}

\section{INTRODUCTION}

$\mathrm{M}$ any patients, especially geriatric and pediatric patients, have difficulty swallowing whole solid oral dosage forms. An effective pharmaceutical dosage form should be considered as a dosing device to enable the accurate and repetitive dosing of drugs. Extemporaneous suspensions, like many other dosage forms, are much more than simple drug carriers, since they may affect the absorption rate and the effectiveness in the patient.

Most of the problems linked with this pharmaceutical form are associated with its physical stability and include dosing accuracy, unknown bioavailability, and lack of access to modified release preparations for pediatric patients, among others (1).

There are few stability studies undertaken on extemporaneous products (1). In this disperse type system, physical change is more important than chemical change. However, it is assumed that suspension stability is primarily governed by the decomposition of the drug dissolved in the aqueous phase (2).

In general, suspension stability determinations consider only factors like changes in chemical stability, visual appearance, $\mathrm{pH}$, caking, and re-dispersability $(3,4)$, with no focus on Dissolution Stability. This term refers to the retention of the dissolution behavior of the dosage form from manufacture to the expiration date (5).

Since suspensions are similar to the disintegrated form of tablets, in vitro dissolution studies are also essential

${ }^{3}$ Corresponding author. when drug particle dissolution is a requirement for bioavailability and, in most cases, the rate-limiting step in absorption (6). In fact, the 1987 FDA Stability Guideline (7) specifically called for dissolution testing of suspensions (Section III.B.6.d). However, there are only a few compendial requirements in pharmacopeial sources for suspension dissolution studies. The United States Pharmacopeia (8) contains 98 monographs for oral suspensions, but only seven of them have a codified dissolution test.

Studies carried out on suspension dissolution (6, 9-15) did not consider if there were any change in this process during the administration period of the reconstituted suspension (stored at room temperature as well as under refrigeration) throughout the shelf life of the powdered product.

Dissolution stability is considered a critical parameter not only from the standpoint of quality control, but also for the impact on the bioavailability of the product, because significant changes of in vitro release profile during storage affect bioavailability. During aging, the absence of dissolution changes provides some assurance that the bioavailability remains intact (5).

Cephalosporins are widely used in suspension dosage forms and are one of the safest and most effective broad-spectrum bactericidal agents. Cefadroxil is a semisynthetic, first-generation cephalosporin antibiotic, the p-hydroxy derivative of cephalexin, with a potential activity against many moderate to mild bacterial infections including staphylococci, streptococci, and enterobacteriae (16). It is slightly soluble in water and in alcohol $(16,17)$. It is well absorbed from the 
gastrointestinal tract. The plasma half-life is about $1.5 \mathrm{~h}$, and more than $90 \%$ of a dose may be excreted unchanged in urine within $24 \mathrm{~h}$ by glomerular filtration, active tubular secretion, and saturable renal tubular reabsorption $(16,18)$. Overall pharmacokinetics is linear only in the $250-500 \mathrm{mg}$ dose range (19).

The first purpose of the present study was to establish the appropriate general conditions for performing the dissolution profiles of extemporaneous cefadroxil suspensions, and then use them as part of a comparative evaluation of commercial product quality. Our research attempted to evaluate the dissolution stability of four different formulations available in the Argentinian market over the recommended administration period of reconstituted forms, mimicking the "in use" stability. The dissolution stability of the powders for reconstitution was evaluated at different times during a year of storage in their original containers, under natural $\left(25^{\circ} \mathrm{C} / 60 \% \mathrm{RH}\right)$ and accelerated $\left(40^{\circ} \mathrm{C} / 75 \% \mathrm{RH}\right)$ aging conditions according to our ICH climatic zone (20).

\section{MATERIALS AND METHODS \\ Reagents and Samples}

Analytical grade potassium hydroxide and monobasic potassium phosphate, and HPLC grade acetonitrile were used (J.T. Baker, USA). Distilled water was used as dissolution medium, and HPLC grade water was used for chromatographic determinations.

Cefadroxil extemporaneous suspensions (dry powder mixture of cefadroxil and excipients for oral suspension, $250 \mathrm{mg} / 5 \mathrm{~mL}$ labeled amount) manufactured by four different pharmaceutical companies (A-D) were purchased from pharmacies in Buenos Aires city (Argentine). All tests were performed within product expiration dates, which were similar among brands.

\section{Deliverable Volume} (8).

This was performed using ten containers of each brand

\section{$\mathrm{pH}$}

The $\mathrm{pH}$ (Altronix TPX-I) was measured over each reconstituted suspension at every stage of dissolution stability evaluation (8).

\section{Visual Inspection}

During the stability study, all samples were visually inspected for signs of caking, color change, and redispersion problems.

\section{Uniformity of Dosage Units-Assay HPLC System and Chromatographic Conditions}

Reversed-phase HPLC was performed on a system consisting of a dual-piston reciprocating Spectra Physics pump (model ISOChrom, USA), a Rheodyne injector (model 7125) with a 20- $\mu$ L loop, a UV-vis Hewlett-Packard detector (model 1050, Japan) set at $230 \mathrm{~nm}$, and a Hewlett-Packard integrator (series 3395, China). Mobile phase consisted of a mixture of pH 5.0 buffer (13.6 g of monobasic potassium phosphate dissolved in $2000 \mathrm{~mL}$ water and adjusted to $\mathrm{pH} 5.0$ with $10 \mathrm{~N}$ potassium hydroxide) and acetonitrile (960:40). Fresh mobile phase was prepared daily, filtered through a 47-mm nylon membrane (0.45- $\mu \mathrm{m}$ pore size, $\mu$ clar, Argentine), and vacuum-degassed before use (8). Separation was performed at room temperature on a Waters Spherisorb ODS (Hypersil) C18 reversed-phase column, 10- $\mu \mathrm{m}$ particle size, $200 \times 4.6 \mathrm{~mm}$ i.d. The column was equilibrated for at least $45 \mathrm{~min}$ with mobile phase flowing through the chromatographic system before starting the assay. All analyses were performed under isocratic conditions at a $0.9 \mathrm{~mL} / \mathrm{min}$ flow rate.

\section{HPLC Standard and Sample Solutions}

Standard solutions were prepared on a weight basis using $\mathrm{pH} 5.0$ buffer as diluent, sonicated for $10 \mathrm{~min}$ at room temperature, and suitably diluted. An appropriate volume was filtered through a $25-\mathrm{mm}$ nylon membrane disposable filter (0.45- $\mu$ m pore size, $\mu$ clar, Argentine). They were injected in triplicate (RSD $<2.0 \%)$ and the results averaged.

Sample solutions were also prepared on a weight basis using $5 \mathrm{~mL}$ of suspension from each bottle after mixing with a standardized manual procedure, and then treated as the standard solutions. Samples mimicked the usual product dose.

In both cases, the theoretical concentration of cefadroxil monohydrate injected was $25-30 \mu \mathrm{g} / \mathrm{mL}$, and all solutions were used on the day prepared.

The uniformity of dosage units was performed using ten containers of each brand (8).

To evaluate chemical stability of the powder under reconstituted suspension form, the assay was performed at these stages:

- At the beginning of the aging process and after 6 and 12 months under specified aging storage conditions; not only at time of reconstitution, but also during the proposed administration period of the reconstituted formulations (at room temperature as well as under refrigeration). This determination was performed on a unique container of each brand.

- Only on freshly prepared suspension, under both aging storage conditions (accelerated and natural). This determination was performed on two reconstituted forms of each brand (for storage at room temperature as well as under refrigeration) and the results averaged.

\section{Dissolution Stability Study \\ Apparatus and Conditions of Dissolution Profiles}

Since "Cefadroxil for oral suspension" has no compendial dissolution method, the USP cefadroxil tablets test (8) was adjusted to this purpose. 
Dissolution profiles were performed on a suitably calibrated USP Apparatus 2 (Vankel VK 7010) at $50 \pm 1$ rpm, under sink conditions in $900 \mathrm{~mL}$ of deaerated distilled water at $37 \pm 0.5^{\circ} \mathrm{C}$, for each test (six replicates of each brand). Samples (10 mL) were withdrawn at 7.5, 15, 30, 45, and $60 \mathrm{~min}$ without replacement of medium and filtered through blue ribbon filter paper.

In order to obtain accurate results, the methodology for drug dissolved quantification was changed to HPLC analysis instead of UV spectroscopy codified for cefadroxil tablets dissolution (8). The solutions obtained were suitably diluted with $\mathrm{pH} 5.0$ buffer, filtered through a 25-mm nylon membrane disposable filter $(0.45-\mu \mathrm{m}$ pore size, $\mu$ clar, Argentine), and injected in triplicate for quantification by the HPLC assay methodology. Results were averaged, and cumulative percentages of drug release calculated.

\section{Schedule of Dissolution Stability Study}

The products were analyzed at the following stages:

0 :

$3 \mathrm{~N}, 6 \mathrm{~N}, 9 \mathrm{~N}, 12 \mathrm{~N}$ :

Beginning of the stability study.

$3 \mathrm{~A}, 6 \mathrm{~A}:$ $3,6,9$, and 12 months of natural $(\mathrm{N})$ aging conditions.

3 and 6 months under accelerated

(A) aging conditions.

Two samples of each brand were reconstituted at every time point of the dissolution stability study and stored at room temperature or under refrigeration. Dissolution determinations were carried out at different times throughout the administration period of the suspension, according to the expiration date stated on each label for the reconstituted form:

- Immediately after reconstitution (suspension freshly prepared).

- Expiration date at room temperature: 7 days for all brands.

- Midpoint of administration period under refrigeration $\left(2-8{ }^{\circ} \mathrm{C}\right): 5$ days (brand A) or 7 days (brands B-D).

- Expiration date under refrigeration $\left(2-8{ }^{\circ} \mathrm{C}\right): 10$ days (brand $A$ ), 14 days (brand $C$ and $D)$, or 15 days (brand $B$ ).

\section{Sample Preparation Procedure for Dissolution Profiles}

Commercially available cefadroxil monohydrate powders for oral suspension were reconstituted with drinking water according to instructions on the label, to a theoretical concentration of $250 \mathrm{mg} / 5 \mathrm{~mL}$, and mixed by a manual shaking procedure prior to sampling. A suspension sample equivalent to a typical dose $(5 \mathrm{~mL})$ was taken on a weight basis using a suitable syringe-cannula system, and quantitatively transferred to the dissolution vessel midway between the surface of the dissolution medium and the top of the rotating blade. To calculate the exact weight of suspension added to the vessel, syringe and cannula were weighed at three stages: empty, filled with the suspension, and after the sample was expelled into the dissolution vessel. The specific gravity of each brand was determined to express the percentage of drug dissolved in the sampled volume $(250 \mathrm{mg} / 5 \mathrm{~mL})$.

\section{RESULTS AND DISCUSSION}

Requirements for deliverable volume were fulfilled by all brands. No important changes in $\mathrm{pH}$ values were recorded throughout the stability study under both aging conditions. Those values remained in the range of 4.0-6.0, satisfying pharmacopeial specifications (8). There were no visual signs of caking after reconstitution during the stability study, and all formulations were easily re-dispersed, even after twelve months of storage of the powders for suspension.

The uniformity of dosage units test was fulfilled by all brands according to USP 29 specifications (8), with results between 106.7 and $110.1 \%$ of the labeled amount, and an RSD within the range of 3.3-3.8\%. Duplicate standards were prepared and injected previously to determine the accuracy of the analysis.

The concentration of cefadroxil measured in the assay of each brand remained within $90 \%$ of the initial value throughout the stability study (Table 1), which indicates that the analyzed powders as well as the reconstituted forms are chemically stable during the administration period at room temperature and under refrigeration according to USP 29 general specifications (8). Nevertheless, to establish if there are differences between the assay average results during the storage period, analysis of variance (ANOVA) was used to compare those values. Statistically significant differences were recorded for assay average values at time of reconstitution (I) only between time zero and $12 \mathrm{~N}$ for brands $\mathrm{A}(P=0.015)$ and $\mathrm{B}$ $(P=0.003)$. The ANOVA results indicate that there were no significant differences throughout the stability study for brands $C(P=0.915)$ and $D(P=0.843)$. None of the four analyzed brands showed statistical differences between I-II or I-IV stages of chemical assay at times $0,6 \mathrm{~N}, 6 \mathrm{~A}$, and $12 \mathrm{~N}$ of storage ( $P$ values ranged from 0.077 to 0.945 ).

All of the analyzed brands except brand D showed a high dissolution rate with large percentages of drug released at early time points of the dissolution profile (Table 2). High variability was found in almost every dissolution measurement of brand $\mathrm{D}$, with relative standard deviations over $20 \%$ in many cases (Table 2 ). For brands $\mathrm{A}$ and $\mathrm{C}$, a few measurements with relative standard deviation greater than $10 \%$ were seen, but none exceeding 20\%; whereas in all cases, these values were less than $10 \%$ for brand $B$ (Table 2). This was the characteristic performance of each analyzed brand all over their dissolution profiles.

Brand D showed significant decreases in some dissolution percentages, with values less than $80 \%$ dissolved at $60 \mathrm{~min}$ and a minimum dissolved percentage of $59 \%$ (Table 2 ).

Analysis of variance (ANOVA) was used to compare the dissolution profiles of cefadroxil from brands $A, B$, and C, in terms of Dissolution Efficiency (D.E.). D.E. is defined as the 
Table 1. Reconstituted Suspension HPLC Assay-Chemical Stability.

\begin{tabular}{|c|c|c|c|c|c|c|c|c|c|}
\hline \multirow[b]{3}{*}{ Storage $^{a}$} & \multirow[b]{3}{*}{ Time $^{b}$} & \multicolumn{8}{|c|}{ Sample } \\
\hline & & \multicolumn{2}{|c|}{ A } & \multicolumn{2}{|c|}{ B } & \multicolumn{2}{|c|}{$C$} & \multicolumn{2}{|c|}{ D } \\
\hline & & $\%^{c}$ & RSD & $\%^{c}$ & RSD & $\%^{c}$ & RSD & $\%^{c}$ & RSD \\
\hline \multirow{4}{*}{0} & I & 109.8 & 1.7 & 110.1 & 1.9 & 108.7 & 1.8 & 107.2 & 2.0 \\
\hline & II & 107.9 & 0.5 & 109.7 & 1.6 & 107.9 & 1.7 & 106.7 & 0.7 \\
\hline & III & 109.4 & 0.8 & 109.7 & 1.6 & 108.0 & 2.0 & 106.9 & 0.7 \\
\hline & IV & 108.1 & 0.05 & 109.0 & 0.5 & 106.1 & 1.3 & 106.2 & 2.8 \\
\hline $3 N$ & I & 110.8 & 1.3 & 111.0 & 1.9 & 109.2 & 2.0 & 107.3 & 1.4 \\
\hline $3 A$ & I & 110.3 & 0.1 & 109.5 & 0.3 & 108.9 & 1.6 & 106.9 & 0.3 \\
\hline \multirow{4}{*}{$6 \mathrm{~N}$} & I & 111.0 & 0.8 & 109.3 & 0.9 & 109.6 & 0.9 & 106.3 & 1.7 \\
\hline & II & 110.7 & 0.1 & 108.8 & 0.5 & 108.8 & 0.4 & 105.3 & 0.4 \\
\hline & III & 109.0 & 0.4 & 109.0 & 0.6 & 108.7 & 0.9 & 105.9 & 0.4 \\
\hline & IV & 109.1 & 0.8 & 108.1 & 0.1 & 108.3 & 1.1 & 104.8 & 0.2 \\
\hline \multirow{4}{*}{$6 A$} & I & 110.8 & 2.0 & 108.0 & 1.1 & 109.8 & 1.8 & 107.1 & 0.4 \\
\hline & II & 109.0 & 1.3 & 108.0 & 0.7 & 109.3 & 0.6 & 105.3 & 0.4 \\
\hline & III & 110.1 & 0.1 & 107.9 & 0.7 & 108.7 & 0.8 & 107.2 & 0.4 \\
\hline & IV & 110.5 & 1.8 & 107.1 & 1.7 & 109.1 & 1.1 & 106.4 & 1.2 \\
\hline $9 \mathrm{~N}$ & I & 108.1 & 1.6 & 108.3 & 1.0 & 108.1 & 1.8 & 106.7 & 1.9 \\
\hline \multirow{4}{*}{$12 \mathrm{~N}$} & I & 105.1 & 1.9 & 105.7 & 0.8 & 108.6 & 1.3 & 106.3 & 1.5 \\
\hline & II & 103.8 & 0.8 & 104.9 & 1.2 & 108.3 & 0.5 & 104.3 & 0.3 \\
\hline & III & 103.2 & 0.3 & 105.7 & 0.3 & 107.5 & 0.7 & 105.2 & 1.3 \\
\hline & IV & 102.9 & 1.2 & 103.9 & 0.1 & 106.9 & 0.04 & 103.1 & 1.2 \\
\hline
\end{tabular}

${ }^{a}$ Months of storage of powder for oral suspension under aging conditions

0 : At the beginning of the aging process.

$\mathrm{N}$ : Natural aging conditions.

A: Accelerated aging conditions.

${ }^{b}$ Stages of analysis of reconstituted forms

I: Immediately after reconstitution.

II: Expiration date at room temperature storage.

III: Midpoint of caducity period under refrigeration.

IV: Expiration date under refrigeration.

c Percentage of label claim.

area under the dissolution curve between two time points expressed as a percentage of the curve at maximum dissolution, $100 \%$, over the same time period (21).

Brand D was not included in the statistical comparison, because the obtained values tended to be heteroscedastic ( $P$ values for Levene test between 0.001 and 0.049), which could also be seen in Table 2 as RSD values greater than $10 \%$ or $20 \%$ in many cases. D. E. average values $(n=6)$ and ANOVA results are summarized in Table 3. There were no statistical differences among D.E. for brand $C$ at different times of powder storage with respect to time zero of the aging study (Table 3). Nevertheless, some significant differences could be observed for brands $A(6 N, 6 A$, and $9 \mathrm{~N}$ with respect to $0 ; P=0.012)$ and $\mathrm{B}(3 \mathrm{~A}$ and $12 \mathrm{~A}$ with respect to $0 ; P=0.012$ ). Over the administration period of the reconstituted suspension, there were no statistical differences between I and II for the three brands, which means that the suspensions were physically stable during storage at room temperature (Table 3, Figures 1-3). Under refrigeration, there were almost no significant differences between I and IV for brands A and C (Table 3, Figures 1 and 3 ), with only a statistical increase in D. E. at time 0 for brand 
Table 2. Cefadroxil Extemporaneous Suspension Dissolution Stability Study

\begin{tabular}{|c|c|c|c|c|c|c|c|c|c|}
\hline \multirow[b]{2}{*}{ Storage $^{a}$} & \multirow[b]{2}{*}{ Time $^{b}$} & \multicolumn{2}{|c|}{ Brand A } & \multicolumn{2}{|c|}{ Brand B } & \multicolumn{2}{|c|}{ Brand C } & \multicolumn{2}{|c|}{ Brand D } \\
\hline & & $\%^{c}$ & RSD & $\%^{c}$ & RSD & $\%^{c}$ & RSD & $\%^{c}$ & RSD \\
\hline \multirow{4}{*}{0} & I & 93 & 12.1 & 98 & 7.9 & 97 & 9.5 & 88 & 11.4 \\
\hline & II & 103 & 2.9 & 97 & 4.9 & 89 & 9.4 & 87 & 23.1 \\
\hline & III & 105 & 14.7 & 105 & 5.4 & 93 & 18.1 & 78 & 21.8 \\
\hline & IV & 108 & 4.1 & 103 & 3.2 & 96 & 7.9 & 59 & 20.2 \\
\hline \multirow{4}{*}{$3 N$} & I & 105 & 4.6 & 100 & 5.9 & 86 & 17.0 & 90 & 4.4 \\
\hline & II & 102 & 8.4 & 102 & 6.4 & 85 & 13.5 & 83 & 17.8 \\
\hline & III & 106 & 5.5 & 102 & 4.7 & 98 & 12.1 & 91 & 5.5 \\
\hline & IV & 109 & 2.5 & 104 & 5.2 & 97 & 4.7 & 80 & 13.6 \\
\hline \multirow{4}{*}{$3 A$} & I & 97 & 7.3 & 94 & 4.5 & 104 & 5.4 & 89 & 7.3 \\
\hline & II & 98 & 5.9 & 94 & 5.1 & 98 & 8.6 & 70 & 15.2 \\
\hline & III & 87 & 6.9 & 100 & 4.5 & 93 & 9.7 & 66 & 8.3 \\
\hline & IV & 99 & 2.9 & 101 & 3.9 & 99 & 3.7 & 60 & 19.7 \\
\hline \multirow{4}{*}{$6 \mathrm{~N}$} & I & 109 & 2.3 & 99 & 5.6 & 98 & 5.2 & 88 & 24.9 \\
\hline & II & 104 & 6.8 & 95 & 4.4 & 96 & 11.5 & 77 & 21.9 \\
\hline & III & 106 & 8.9 & 97 & 4.2 & 101 & 6.5 & 92 & 3.7 \\
\hline & IV & 109 & 7.7 & 107 & 3.7 & 98 & 7.2 & 76 & 20.1 \\
\hline \multirow{4}{*}{$6 A$} & I & 106 & 4.5 & 100 & 4.7 & 91 & 11.2 & 96 & 11.6 \\
\hline & II & 104 & 4.5 & 100 & 6.4 & 91 & 12.4 & 73 & 22.3 \\
\hline & III & 106 & 1.6 & 99 & 4.1 & 98 & 10.3 & 89 & 11.3 \\
\hline & IV & 106 & 3.6 & 96 & 5.6 & 103 & 6.5 & 88 & 11.5 \\
\hline \multirow{4}{*}{$9 N$} & I & 106 & 9.0 & 102 & 2.5 & 96 & 10.4 & 89 & 16.7 \\
\hline & II & 102 & 12.8 & 100 & 5.6 & 99 & 3.9 & 85 & 11.3 \\
\hline & III & 104 & 0.9 & 105 & 4.5 & 96 & 12.0 & 89 & 9.5 \\
\hline & IV & 104 & 3.3 & 103 & 3.1 & 93 & 9.1 & 83 & 16.1 \\
\hline \multirow{4}{*}{$12 \mathrm{~N}$} & I & 101 & 7.1 & 101 & 3.3 & 96 & 10.8 & 71 & 14.9 \\
\hline & II & 99 & 2.7 & 98 & 4.1 & 100 & 6.9 & 69 & 21.6 \\
\hline & III & 94 & 6.7 & 97 & 5.6 & 107 & 7.6 & 80 & 7.7 \\
\hline & IV & 102 & 2.9 & 99 & 4.2 & 103 & 3.7 & 77 & 16.5 \\
\hline $\begin{array}{l}{ }^{a} \text { Months } \\
\text { 0: At the } \\
\text { N: Storag } \\
\text { A: Storag } \\
{ }^{b} \text { Stages of } \\
\text { I: Imme } \\
\text { II: Expira } \\
\text { III: Midpc } \\
\text { IV: Expira } \\
\text { c Percenta }\end{array}$ & $\begin{array}{l}\text { rage of } p \\
\text { inning of } \\
\text { der natu } \\
\text { der acce } \\
\text { ysis of re } \\
\text { ly after } r \\
\text { date at rc } \\
\text { f caducit } \\
\text { date und }\end{array}$ & $\begin{array}{l}\text { roral } \\
\text { proce } \\
\text { conditi } \\
\text { ing co } \\
\text { d susp } \\
\text { ion (fre } \\
\text { eratur } \\
\text { inder r } \\
\text { ation. }\end{array}$ & $\begin{array}{l}\text { pared } \\
\text { tion. }\end{array}$ & n). & & & & & \\
\hline
\end{tabular}


Table 3. Dissolution Stability Study of Cefadroxil Extemporaneous Suspension. ANOVA Comparisons between D. E. Average Values $(n=6)$.

\begin{tabular}{|c|c|c|c|c|c|c|c|c|}
\hline Sample & Storage $^{a}$ & $I^{b}$ & $\Delta 0^{c}$ & $\mathrm{II}^{b}$ & I vs. II & $\mathrm{III}^{b}$ & $I^{b}$ & I vs. IV ${ }^{c}$ \\
\hline \multirow{8}{*}{ A } & 0 & 87.79 & ------------ & 92.32 & n.s. & 93.73 & 96.52 & $* *(p=0.002)$ \\
\hline & $3 N$ & 94.01 & n.s. & 91.65 & n.s. & 95.55 & 97.47 & n.s. \\
\hline & $3 A$ & 86.61 & n.s. & 88.17 & n.s. & 76.85 & 87.71 & n.s. \\
\hline & $6 \mathrm{~N}$ & 97.59 & ${ }^{*}(p=0.012)$ & 93.52 & n.s. & 94.31 & 100.40 & n.s. \\
\hline & $6 \mathrm{~A}$ & 95.08 & $*(p=0.012)$ & 93.76 & n.s. & 94.23 & 95.13 & n.s. \\
\hline & $9 \mathrm{~N}$ & 95.29 & $*(p=0.012)$ & 91.92 & n.s. & 93.58 & 93.23 & n.s. \\
\hline & $12 \mathrm{~N}$ & 90.02 & n.s. & 88.66 & n.s. & 83.94 & 90.98 & n.s. \\
\hline & $12 \mathrm{~A}$ & 89.72 & n.s. & 82.44 & n.s. & ----------- & ----------- & ------------ \\
\hline \multirow{8}{*}{ B } & 0 & 90.75 & ----------- & 90.02 & n.s. & 95.31 & 94.19 & n.s. \\
\hline & $3 N$ & 89.82 & n.s. & 92.90 & n.s. & 92.46 & 94.22 & $*(p=0.039)$ \\
\hline & $3 A$ & 85.00 & $*(p=0.012)$ & 84.49 & n.s. & 91.08 & 92.32 & $* *(p=0.001)$ \\
\hline & $6 \mathrm{~N}$ & 89.08 & n.s. & 87.06 & n.s. & 88.48 & 96.19 & $* *(p=0.001)$ \\
\hline & $6 \mathrm{~A}$ & 90.23 & n.s. & 89.83 & n.s. & 90.32 & 87.72 & n.s. \\
\hline & $9 N$ & 91.96 & n.s. & 91.25 & n.s. & 94.40 & 93.79 & n.s. \\
\hline & $12 \mathrm{~N}$ & 90.69 & n.s. & 89.14 & n.s. & 87.33 & 89.26 & n.s. \\
\hline & $12 \mathrm{~A}$ & 85.58 & $*(p=0.012)$ & 88.88 & n.s. & ------------ & ------------ & ------------ \\
\hline \multirow{8}{*}{$\mathrm{C}$} & 0 & 85.41 & ------------- & 79.42 & n.s. & 87.64 & 87.85 & n.s. \\
\hline & $3 N$ & 80.54 & n.s. & 75.76 & n.s. & 84.77 & 86.15 & n.s. \\
\hline & $3 A$ & 92.85 & n.s. & 87.32 & n.s. & 82.93 & 88.05 & n.s. \\
\hline & $6 \mathrm{~N}$ & 86.95 & n.s. & 85.50 & n.s. & 89.41 & 88.39 & n.s. \\
\hline & $6 \mathrm{~A}$ & 81.06 & n.s. & 79.84 & n.s. & 86.52 & 91.73 & $* *(p=0.002)$ \\
\hline & $9 \mathrm{~N}$ & 85.53 & n.s. & 88.58 & n.s. & 86.01 & 83.55 & n.s. \\
\hline & $12 \mathrm{~N}$ & 88.16 & n.s. & 89.40 & n.s. & 94.61 & 91.81 & n.s. \\
\hline & $12 \mathrm{~A}$ & 88.08 & n.s. & 85.14 & n.s. & ----------- & ----------- & ----------- \\
\hline $\begin{array}{l}{ }^{a} \text { Months } \\
\text { 0: Begin } \\
\text { N: Storac } \\
\text { A: Storac } \\
{ }^{b} \text { Stage of } \\
\text { I: Imme } \\
\text { II: Expira } \\
\text { III: Midpc } \\
\text { IV: Expi } \\
\text { c Statistica } \\
\text { n.S.: The } \\
\text { *: Ther } \\
\text { **: Ther }\end{array}$ & $\begin{array}{l}\text { of powder } \\
\text { e aging pro } \\
\text { tatural agin } \\
\text { accelerated } \\
\text { f reconstitu } \\
\text { ter reconsti } \\
\text { at room ter } \\
\text { lucity perio } \\
\text { te under ref } \\
\text { es } \\
\text { gnignificant di } \\
\text { gh significa }\end{array}$ & $\begin{array}{l}\text { al susper } \\
\text { itions. } \\
\text { conditio } \\
\text { pension } \\
\text { freshly p } \\
\text { ure stora } \\
r \text { refrige } \\
\text { on. } \\
\text { nces be } \\
\text { es ( } P \text { valc } \\
\text { rences ( }\end{array}$ & $\begin{array}{l}\text { he compare } \\
\text { veen } 0.01 \text { ar } \\
\text { less than } 0\end{array}$ & & & & & \\
\hline
\end{tabular}

A $(P=0.002)$ and at time 6 A for brand $C(P=0.002)$. For brand $B$, the ANOVA results indicate that there were significant increases in D. E. average values from I to IV at times $3 \mathrm{~N}(P=0.039), 3 \mathrm{~A}(P=0.001)$, and $6 \mathrm{~N}(P=0.001)$ of storage (Table 3, Figure 2). There were no significant decreases in D. E. throughout the administration period of the reconstituted forms of the three brands under refrigeration (Table 3 ). 


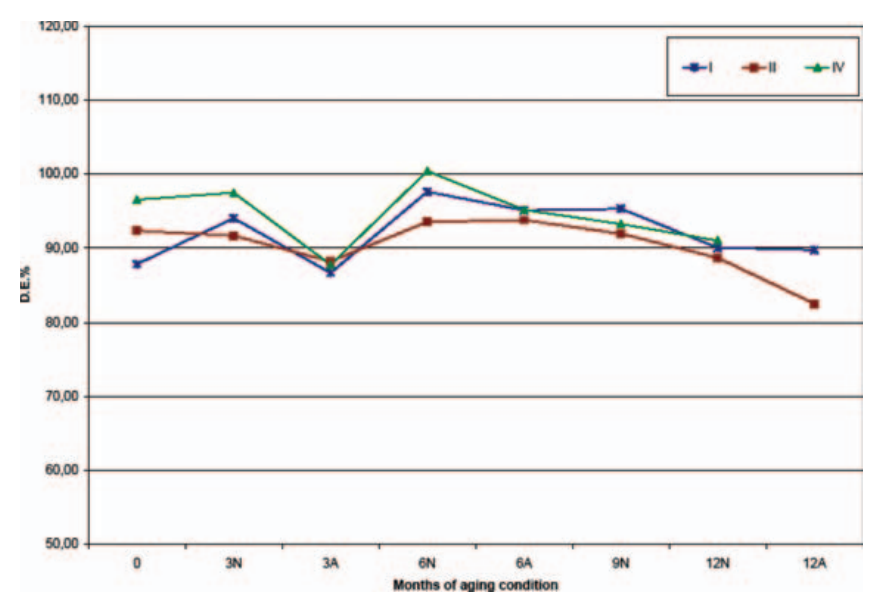

Figure 1.D. E. evolution for Sample A throughout the expiration period of cefadroxil suspension during aging study.

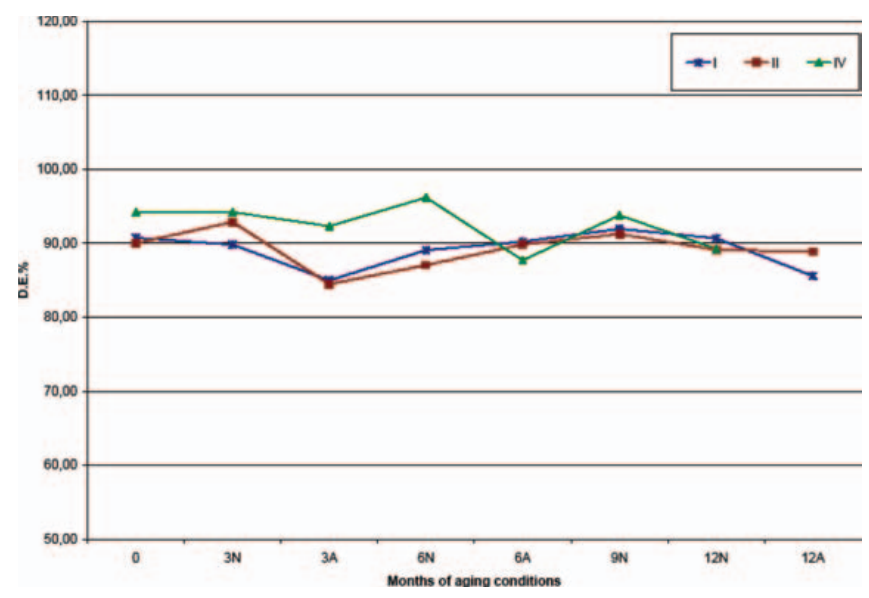

Figure 2. D. E. evolution for Sample B throughout the expiration period of cefadroxil suspension during aging study.

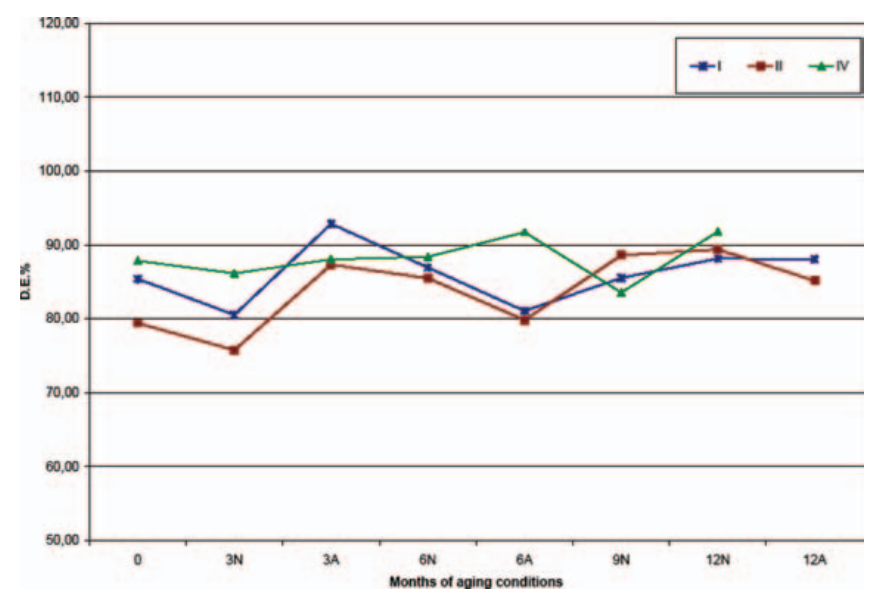

Figure 3. D. E. evolution for Sample C throughout the expiration period of cefadroxil suspension during aging study.
As expected, when a product is stored under the conditions specified on the label, it has to retain the initial dissolution behavior throughout its shelf life. This has been confirmed by our results for brands $A, B$, and C at each stage of testing. Despite some decreases in dissolution percentages, no value less than $80 \%$ significantly decreased from stage I was observed for those three brands, at any storage time.

Nevertheless, significant decreases in dissolution percentages, associated with a high variability, were observed for brand D throughout the administration period of the reconstituted form at room temperature as well as under refrigeration (Table 2, Figure 4), which could impact its bioavailability.

\section{CONCLUSIONS}

All analyzed formulations fulfilled the requirements of the assay, uniformity of dosage units, deliverable volume determination, and stability of $\mathrm{pH}$ values of reconstituted suspension. Visually, all samples remained homogeneous after reconstitution and did not exhibit signs of caking throughout the year of storage as powders for oral suspension.

The analyzed powders for oral suspension were chemically stable throughout the year of storage under both aging conditions and after reconstitution. Brands $\mathrm{A}$, $B$, and $C$ also had acceptable dissolution stability when stored at room temperature or under refrigeration throughout their expiration periods as reconstituted forms. On the other hand, the only formulation with undesirable dissolution stability was brand D, which showed high variability in the dissolution pattern during the administration period as well as over a year of storage.

The potential impact on the in vivo bioavailability and the possible factors that may be generating these differences in the dissolution stability of this brand (e.g., particle-size or surface-area differences, changes in drug particle size with time, method of manufacture,

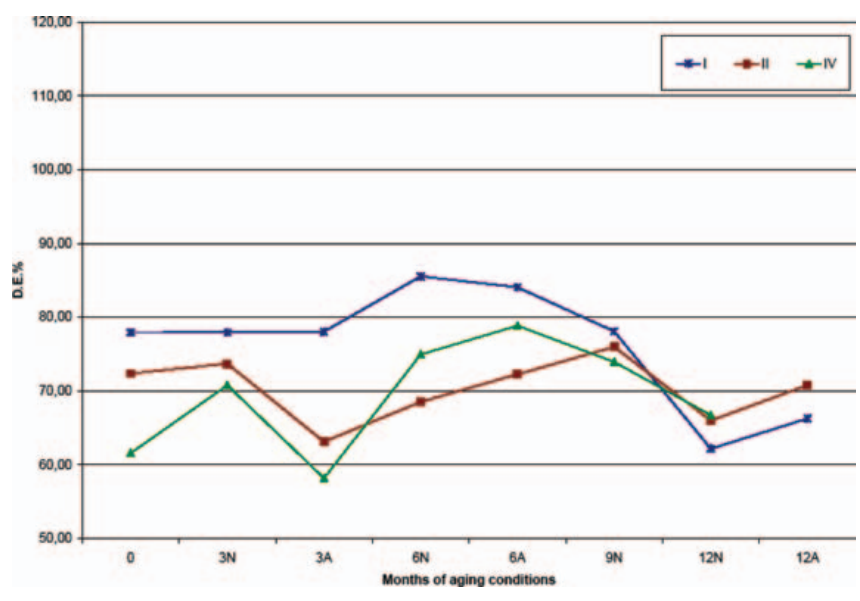

Figure 4. D. E. evolution for Sample D throughout the expiration period of cefadroxil suspension during aging study. 
composition of inactive components, and possible interactions with cefadroxil) may warrant further investigation.

\section{ACKNOWLEDGMENTS}

Noelia Gonzalez Vidal holds a doctoral fellowship of the Consejo Nacional de Investigaciones Científicas y Técnicas (CONICET) and Universidad Nacional del Sur (UNS), Argentine.

\section{REFERENCES}

1. Standing, J. F.; Tuleu, C. Paediatric formulationsGetting to the heart of the problem.Int. J.Pharm. 2005, 300, 56-66.

2. Carstensen, J.T.Disperse and Aggregated Systems. In Drug Stability Principles and Practices, 2nd ed.; Marcel Dekker, Inc: New York, 1995; pp 163-195.

3. Nahata, M. C.; Jackson, D. S. Stability of cefadroxil in reconstituted suspension under refrigeration and at room temperature. Am. J. Hosp. Pharm. 1991, 48 (5), 992-993.

4. Boonme, P.; Phadoongsombut, N.; Phoomborplub, P.; Viriyasom, S. Stability of extemporaneous norfloxacin suspension. Drug Dev. Ind. Pharm. 2000, 26 (7), 777-779.

5. Murthy, K. S.; Ghebre-Sellassie, J. Current perspectives on the dissolution stability of solid oral dosage forms. J. Pharm. Sci. 1993, 82 (2), 113-126.

6. Cárdenas, R. H. L.; Cortés, A. A. R.; Argotte, R. R.; Luna, M.P.; Dominguez, R. A. Investigation of dissolution profiles from suspensions containing benzoyl metronidazole using a statistical model with repeated measurements. Drug Dev. Ind. Pharm. 1994, 20 (6), 1063-1073.

7. Guideline for Submitting Documentation for the Stability of Human Drugs and Biologics; Guidelines for Industry; U.S. Department of Health and Human Services, Food and Drug Administration, U.S. Government Printing Office:Washington, DC, February 1987.

8. United States Pharmacopeia and National Formulary USP 29-NF 24, Spanish ed.; The United States Pharmacopeial Convention, Inc.: Rockville, MD, 2006.

9. Howard, S. A.; Mauger, J.W.; Phusanti, L. Dissolution profiles for multisized prednisolone acetate suspensions. J. Pharm. Sci. 1977, 66 (4), 557-559.

10. Strum, J. D.; Colaizzi, J. L.; Goehl, T. J.; Jaffe, J. M.; Pitlick, W. H.; Shah, V. P.; Poust, R. I. Bioavailability of sulfonamide suspensions I: Dissolution profiles of sulfamethizole using paddle method.J. Pharm.Sci. 1978, 67 (10), 1399-1402.

11. Mathur, L. K.; Jaffe, J. M.; Poust, R. I.; Barry, H. $3^{\text {rd }}$; Goehl, T. J.; Shah, V.P.; Colaizzi, J. L. Bioavailability and dissolution behavior of trisulfapyrimidine suspensions. J. Pharm. Sci. 1979, 68 (6), 699-702.

12. Meshali, M.; El-Sabbagh, H.; Ghanem, A.; Foda, A. Simultaneous in vitro and in vivo evaluation of both trimethoprim and sulfamethoxazole from certain dosage forms. Pharmazie 1983, 38 (6), 403-406.

13. Ezzedeen, F.W.; Majeed, S. H.; Shihab, F.A.; Mahmoud, M. J.; Robinson, D. H.; Tahseen, Y. H.; Stohs, S. J. In vitro and in vivo evaluation of four co-trimoxazole oral suspensions. Int. J. Pharm. 1990, 59 (3), 255-261.

14. Boonme, P.; Phadoongsombut, N.; Ingkatawornwong, S.; Faroongsarng, D. The formulation development and stability study of Norfloxacin suspension. Thammasat Int. J.Sc. Tech. 2002, 7 (1), 1-4.

15. Danckwerts, M. P.; Ebrahim, S.; Pillay, V. Pharmaceutical formulation of a fixed-dose anti-tuberculosis combination. Int. J.Tuberc. Lung Dis. 2003, 7 (3), 289-297.

16. Martindale: The Complete Drug Reference, 32nd ed.; Parfitt, K., Ed.; Pharmaceutical Press: London, 1999.

17. Sinko, P. J.Cefadroxil. In Chemical Stability of Pharmaceuticals: A Handbook for Pharmacists, 2nd ed.; Connors, K. A., Amidon, G. L., Stella, V. J., Eds.; John Wiley \& Sons: New York, 1986; pp 295-301.

18. Granero, L.; Gimeno, M. J.; Torres-Molina, F. Chesa-Jimenez, J.; Peris, J.E. Studies on the renal excretion mechanisms of Cefadroxil. Drug Metab. Dispos. 1994, 22 (3), 447-450.

19. La Rosa, F.; Ripa, S.; Prenna, M.; Ghezzi, A.; Pfeffer, M. Pharmacokinetics of Cefadroxil alter oral administration in humans. Antimicrob. Agents Chemother. 1982, 21 (2), 320-322.

20. International Conference on Harmonisation of Technical Requirements for Registration of Pharmaceuticals for Human Use. Stability Testing of New Drug Substances and Products, Q1A (R2); ICH Harmonised Tripartite Guideline; Geneva, Switzerland, 2003. http://www.ich.org/LOB/media/MEDIA419.pdf (accessed Jun 27, 2008).

21. Khan, K. A.The concept of dissolution efficiency.J. Pharm. Pharmacol. 1975, 27 (1), 48-49. 